\title{
Analysis of Secondary Interactions and Structure-Activity-Relationship of Two Benzoic Acids
}

\author{
J. DINESH*
}

Department of Physics, Govt. G.M. Science College, Jammu-180 001, India

(Received February 11, 2012; in final form February 5, 2013)

\begin{abstract}
Two benzoic acids, 2-[3-(o-methylphenoxymethyl)-5-phenyl-[1,2,4]triazol-4-yl]-benzoic acid [I] and 2-[3-(m-methylphenoxymethyl)-5-phenyl-[1,2,4]triazol-4-yl]-benzoic acid [II] were synthesized and their crystal structures have been analyzed to the reliability factor of $4.2 \%$ [I] and $4.8 \%$ [II]. Different structural motifs (i.e. chains, dimmers, rings, etc.) bonded through $\mathrm{C}-\mathrm{H} \ldots \pi, \pi \ldots \pi$ and hydrogen interactions have been analyzed. Structure-activity-predictions have been identified on the basis of structural fragments and variation in activities has been observed in both the compounds. The detailed analysis of non-covalent interactions illustrates that the shifting of methyl group from ortho-to-para increases the bioactivity-predictions of "Endothelin B receptor antagonist".
\end{abstract}

DOI: 10.12693/APhysPolA.123.704

PACS: 61.66.Fn

\section{Introduction}

Benzoic acid derivatives are useful agents for experimental studies of both cancer prevention and treatment, as well as for investigation of the mechanism of action of retinoids in the control of cell differentiation [1]. Benzoic acid derivatives were found in active extract fractions [2]. The benzoic acid derivatives have wide spectrum of biological activities such as antitumor, antimicrobial, antihelmintic, antileishmanial, anticonvulsant and anti-inflammatory [3]. The present study is a part of our on-going research on the biological-activity-relationships and structural motifs [4]. The study was aimed at increasing on understanding of biological activities of meta and para substituents of benzoic acid derivatives. The ortho substituents are often unreliable due to their direct interactions with the functional groups. The meta substituents are dominated by inductive effects (i.e. both electron withdrawing or donating) and para substituents are often associated with resonance stabilization and minimal transferability, therefore not generally of interest.

Biological-activity-spectrum is a concept that provides the rationale for predicting many biological activity types for different compounds. Within this concept the biological activity is considered to be an intrinsic property of the compound, depending only on its structure. Any component of this biological activity spectrum of a given compound is assumed to be detectable under suitable experimental conditions. By using a qualitative representation of biological activity, it is possible to compare and mix activity data for obtaining robust quantitative models. The crystal structures can be described by descriptors called multilevel neighborhoods of atoms (MNA) [5]. The MNA descriptors represent various structure property relation-

*e-mail: phy.dinesh.ap@gmail.com ships including many types of biological activity [6], mutagenicity and carcinogenicity [7], drug-likeness [8], etc.

\section{Experimental}

\subsection{Synthesis of compound I}

A mixture of anthranilic acid $(0.1 \mathrm{~mol})$ and benzoyl chloride $(0.1 \mathrm{~mol})$ was added in benzene $(35 \mathrm{ml})$ and trimethylamine $(0.5 \mathrm{ml})$ which has been heated on water bath for $3.5 \mathrm{~h}$. The solution then cooled and separated solid was filtered and further recrystallized from ethanol to get 2-phenyl-3,1-benzoxazin-4-one. The mixture of 2-phenyl-3-benzoxazin-4-one $(0.1 \mathrm{~mol})$ and $o$-methylphenoxyacetic acid hydrazide $(0.1 \mathrm{~mol})$ in methanol was refluxed for $8 \mathrm{~h}$, cooled and separated solid filtered and recrystallized from ethanol.

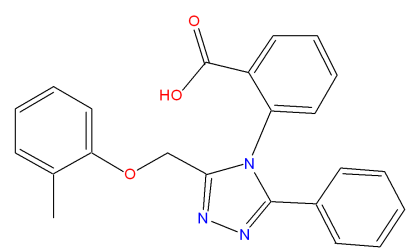

2-[3-(o-methylphenoxymethyl)-5-phenyl-[1,2,4] triazol-4-yl]-benzoic acid

\subsection{Synthesis of compound II}

A mixture of anthranilic acid $(0.1 \mathrm{~mol})$ and benzoyl chloride $(0.1 \mathrm{~mol})$ was added in benzene $(30 \mathrm{ml})$ and trimethyl amine $(0.5 \mathrm{ml})$ which has been heated on water bath for $3 \mathrm{~h}$. The solution then cooled and separated solid was filtered and further recrystallized from ethanol to get 2-phenyl-3,1-benzoxazin-4-one. The mixture of 2-phenyl-3-benzoxazin-4-one $(0.1 \mathrm{~mol})$ and $m$-methylphenoxyacetic acid hydrazide $(0.1 \mathrm{~mol})$ in methanol was refluxed for $6 \mathrm{~h}$, cooled and separated solid filtered and recrystallized from ethanol. 


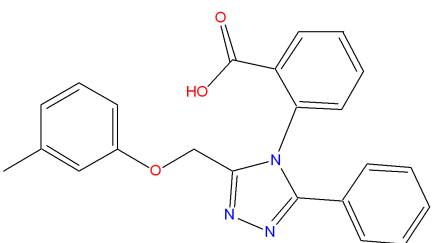

2-[3-(m-methylphenoxymethyl)-5-phenyl-[1,2,4] triazol-4-yl]-benzoic acid

\subsection{Structure analysis}

Single crystal X-ray crystallographic techniques have been employed for the crystal structure determination and refinement. Morphologically perfect single crystal has been selected for the three-dimensional X-ray diffraction data by using X-calibur CCD diffractometer. For both the compounds, the structure determination has been carried by SHELXS program [9] whereas the least-squares refinement has been contemplated by using SHELXL program [10] for the precise values of $R$-factor ( $4.2 \%$ for I and $4.8 \%$ for II). All the non-hydrogen atoms of the molecule were located from $E$-map. The positional and thermal parameters of non-hydrogen atoms were refined anisotropically. All the hydrogen atoms included in the final cycles of the refinement were constrained to ride on their parent atoms, with $U_{\text {iso }}(H)=\mathrm{X} U_{\text {eq }}$ (parent), where $\mathrm{X}=1.5$ for methyl and 1.2 for all others. Constrained distances were $\mathrm{O}-\mathrm{H}=0.82 \AA$ and $\mathrm{C}-\mathrm{H}=0.93 \AA$ but for $\mathrm{C} 19-\mathrm{H}=0.97 \AA$. The experimental and structural data for both the compounds has been presented in Table I. The 3D view depicting the atomic numbering scheme of compound I and II is presented in Fig. 1a and $b$, respectively.

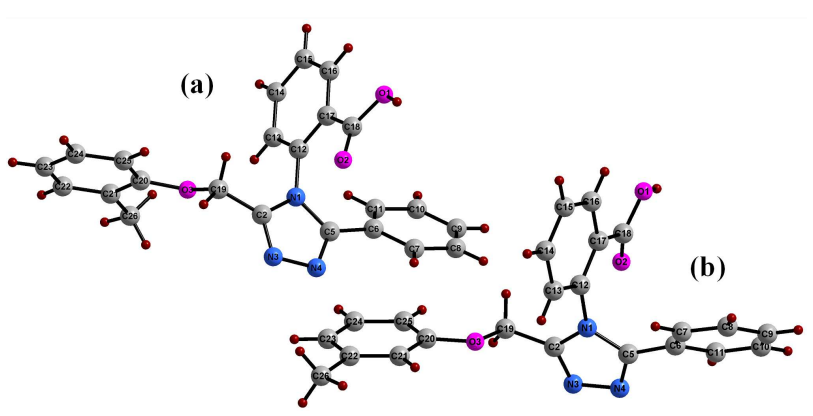

Fig. 1. (a) 3D view of the compound I showing the atomic numbering scheme. (b) $3 \mathrm{D}$ view of the compound II showing the atomic numbering scheme.

Experimental data of compound I and II.

\begin{tabular}{c|c|c}
\hline \hline Experimental data & Compound I & Compound II \\
\hline empirical formula & $\mathrm{C}_{23} \mathrm{H}_{19} \mathrm{~N}_{3} \mathrm{O}_{3}$ & $\mathrm{C}_{23} \mathrm{H}_{19} \mathrm{~N}_{3} \mathrm{O}_{3}$ \\
formula weight & 385.41 & 385.41 \\
temperature & $293(2) \mathrm{K}$ & $295(2) \mathrm{K}$ \\
wavelength & $0.71073 \AA$ & $0.71069 \AA$ \\
crystal system, space group & monoclinic, $P 2_{1} / c$ & orthorhombic, Pbca \\
unit cell dimensions & $a=19.118(4) \AA, \alpha=90^{\circ}$ & $a=13.589(9) \AA, \alpha=90^{\circ}$ \\
& $b=7.971(2) \AA, \beta=86.35(2)^{\circ}$ & $b=18.546(6) \AA, \beta=90^{\circ}$ \\
volume & $c=13.149(4) \AA, \gamma=90^{\circ}$ & $c=16.075(8) \AA, \gamma=90^{\circ}$ \\
$Z$, calculated density & $1999.7(10) \AA 3$ & $4051(4) \AA{ }^{3}$ \\
absorption coefficient & $4,1.280 \mathrm{Mg} / \mathrm{m}^{3}$ & $8,1.264 \mathrm{Mg} / \mathrm{m}^{3}$ \\
$F(000)$ & $0.087 \mathrm{~mm} \mathrm{~m}^{-1}$ & $0.085 \mathrm{~mm}^{-1}$ \\
crystal size & 808 & 1616 \\
$\theta$-range for data collection & $0.35 \times 0.30 \times 0.25 \mathrm{~mm}^{3}$ & $0.5 \times 0.45 \times 0.3 \mathrm{~mm}^{3}$ \\
limiting indices & $2.13-24.99^{\circ}$ & $2.20-24.97^{\circ}$ \\
reflections collected/unique & $\leq h \leq 22,0 \leq k \leq 9,0 \leq l \leq 15$ & $0 \leq h \leq 16,0 \leq k \leq 22,0 \leq l \leq 19$ \\
data/restraints/parameters & $3693 / 3519$ & $3548 / 3548$ \\
goodness-of-fit on $F^{2}$ & $3519 / 0 / 263$ & $3548 / 0 / 262$ \\
final $R$ indices [ $\left.F_{0}>4 \sigma F_{0}\right]$ & 1.038 & 0.911 \\
$R$ indices (all data) & $R=0.0428, w R=0.1036$ & $R=0.0482, w R=0.0974$ \\
largest diff. peak and hole & $R=0.0714, w R=0.1167$ & $R=0.1403, w R=0.1201$ \\
& 0.146 and $-0.183 \mathrm{e} \AA{ }^{-3}$ & 0.157 and $-0.174 \mathrm{e} \AA^{-3}$
\end{tabular}

\subsection{Bioactivity predictions}

The three-dimensional coordinate data of both the compounds have been selected as an input for the PASS software [11] to predict the bioactivity relationship. On the basis of the $x, y, z$ coordinates, the molecular structure has been drawn and the bioactivity predictions were determined on the statistics of MNA descriptors for active and inactive fragments. The biological activity spec- 
tra for substances have been correlated on structure-activity relationships data and knowledge (SAR) base which provides the different $P_{a}$ (possibility of activity) and $P_{i}$ (possibility of inactivity) values. The influence of these descriptors can be positive (if they were found in compounds with particular activity) or negative (if the descriptors were found in compounds without the particular activity) or even neutral. The possible activity predictions with $P_{a}$ and $P_{i}$ values for the both the benzoic acid derivatives are given in Table II.

TABLE II

Possible-activity-predictions with $P_{a}$ and $P_{i}$ values.

\begin{tabular}{c|c|c|c}
\hline \hline S.No. & $P_{a}$ & $P_{i}$ & Activity \\
\hline \multicolumn{3}{c}{ Compound I } \\
\hline 1 & 0.368 & 0.035 & antihypertensive \\
2 & 0.224 & 0.074 & diuretic \\
3 & 0.160 & 0.005 & vasopressin 1 antagonist \\
4 & 0.167 & 0.032 & guanylate cyclase stimulant \\
5 & 0.103 & 0.008 & antidiuretic hormone antagonist \\
6 & 0.126 & 0.036 & phosphodiesterase V inhibitor \\
7 & 0.185 & 0.163 & neuropeptide Y antagonist \\
8 & 0.025 & 0.015 & angiotensin antagonist \\
9 & 0.023 & 0.015 & angiotensin II receptor antagonist \\
\hline \multicolumn{3}{|c}{ Compound II } \\
\hline 1 & 0.370 & 0.034 & antihypertensive \\
2 & 0.226 & 0.072 & diuretic \\
3 & 0.171 & 0.005 & vasopressin 1 antagonist \\
4 & 0.138 & 0.027 & phosphodiesterase V inhibitor \\
5 & 0.111 & 0.007 & antidiuretic hormone antagonist \\
6 & 0.138 & 0.067 & guanylate cyclase stimulant \\
7 & 0.192 & 0.149 & neuropeptide Y antagonist \\
8 & 0.024 & 0.017 & angiotensin antagonist \\
9 & 0.021 & 0.017 & angiotensin II receptor antagonist \\
10 & 0.080 & 0.070 & endothelin B receptor antagonist
\end{tabular}

\section{Discussion}

Both the compounds have analogous values of bond distances and bond angles [12-14]. The slight change in bond length between phenyl ring and carboxyl group in compound I [1.498(2) $\AA]$ and II $[1.505(3) \AA]$ could be due to the antiparallel arrangement of $\mathrm{X}-\mathrm{H}$. . A interactions along 010 and 001 directions, respectively. In both the compounds, the carboxyl group is more inclined towards C16 instead of C12. The methyl group inclined, at ortho position in compound I, is tilted towards C20 instead of $\mathrm{C} 22$ and at para position in compound II has more inclination towards $\mathrm{C} 21$ instead of $\mathrm{C} 23$. In compound I, the intermolecular $\mathrm{O}-\mathrm{H}$...N hydrogen bonded pattern depicting the zigzag chains along the $a c$-plane has been observed as shown in Fig. 2a whereas the $\mathrm{O}-\mathrm{H}$.... N bonded zigzag chains have been plotted down $a b$-plane for compound II as shown in Fig. 2b. In both the compounds, antiparallel arrangement of $1 \mathrm{D}$ chains has been observed. The 1D chains are separated by distance of
$12.86 \AA$ from one another in compound I. The interplanar angle $\left[1.6^{\circ}\right]$ between two chains confirms the planarity between them. In compound II, the $1 \mathrm{D}$ chains are separated from one another by a distance of $13.47 \AA$ and the interplanar angle between them has been calculated to $0.5^{\circ}$.

(a)
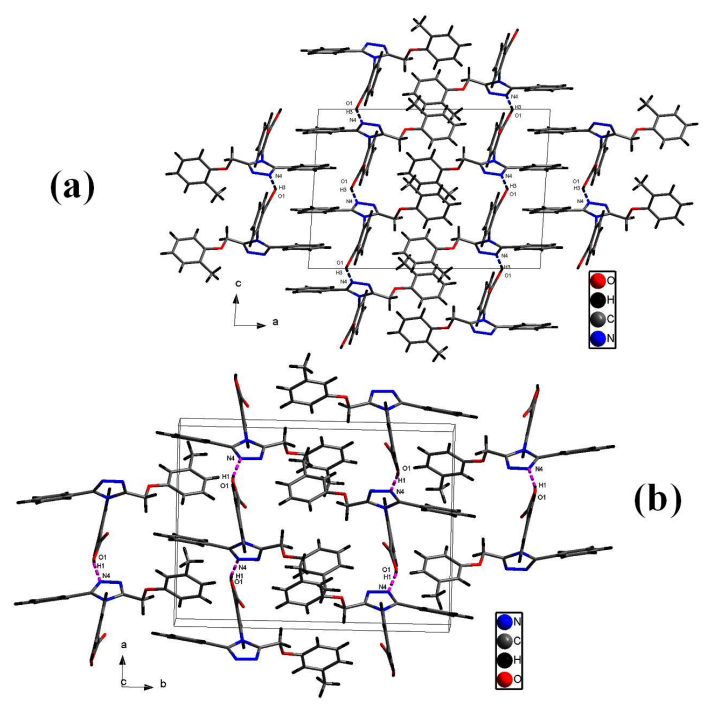

Fig. 2. (a) O-H...N hydrogen bonded $1 \mathrm{D}$ chains down $b$-axis in compound I, (b) O-H. ..N hydrogen bonded 1D chains down $c$-axis in compound II.

In compound I, linear chains bonded through $\mathrm{C}-\mathrm{H}$... $\pi$ interactions have been drawn along $a c$-plane as shown in Fig. 3a. The $\mathrm{C} 15$ atom of the phenyl ring acts as hydrogen donor whereas the centroid of the triazole moiety acts as acceptor with $d=2.934 \AA$. The linear chains comprise of $\mathrm{C}-\mathrm{H} . . \pi$ interactions are separated by a distance of $10.34 \AA$ from one another. In compound II, the $\mathrm{C}-\mathrm{H}$. . . $\pi$ interactions are formed between the $\mathrm{C} 24$ atom and the centroid of the phenyl moiety containing carboxyl group. The dimer pattern of $\mathrm{C}-\mathrm{H}$. . $\pi$ interactions has been observed along $b c$-plane as shown in Fig. 3b.

The formation of $\pi \ldots \pi$ interactions have been observed in compound I (Fig. 4) whereas $\pi \ldots \pi$ interaction pattern is missing in compound II, since the minimum centroid-centroid distance is 4.394(4) $\AA$ between $\mathrm{Cg} 2 \ldots \mathrm{Cg} 4$ at symmetry position $1 / 2-x,-1 / 2+y, z$. The $\mathrm{Cg} 2 \ldots \mathrm{Cg} 2$ interaction is formed at symmetry position of $-x, 2-y, 1-z$ and the $\mathrm{Cg} 4 \ldots \mathrm{Cg} 4$ interaction has been formed at $1-x, 2-y, 1-z$. In case of $\mathrm{Cg} 2 \ldots \mathrm{Cg} 2$, the ring centroid-centroid distance is $3.659(2) \AA$ for the atoms $\mathrm{C} 6-\mathrm{C} 11$ and the centroidcentroid slippage is $0.817 \AA$. The centroid-centroid distance is $3.894(2) \AA$ in case of $\mathrm{Cg} 4$...Cg4 (ring atoms C20-C25) interactions with centroid-centroid slippage of $1.292 \AA$. The dimer pattern has been formed through $\mathrm{Cg} 2 \ldots \mathrm{Cg} 2$ and $\mathrm{Cg} 4 \ldots \mathrm{Cg} 4$ interactions and the minimum dimer-to-dimer distance is 8.009(3) $\AA$.

The 1,2,4-triazoles are associated with diverse pharmacological activities such as antibacterial, antifungal and 


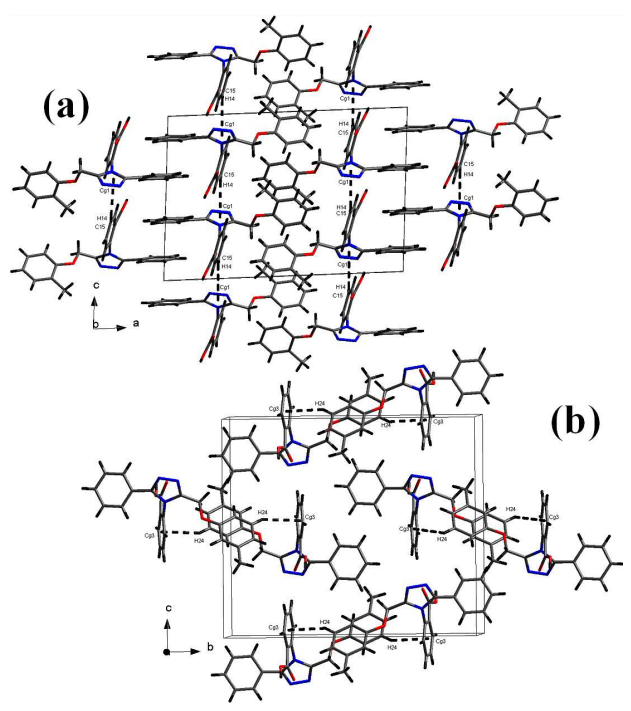

Fig. 3. (a) Linear chain bonded through C-H... interactions along 010 directions. (b) Dimer pattern formed through $\mathrm{C}-\mathrm{H} . . \pi$ interactions along 100 directions.

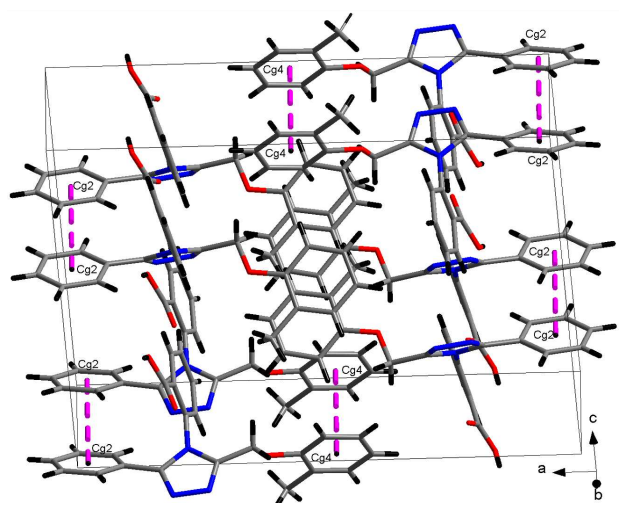

Fig. 4. Dimer pattern formed by $\pi \ldots \pi$ interactions.

anti-inflammatory activity $[15,16]$. The compounds I and II show the positive values of antihypertensive and diuretic activities as shown in Fig. 5. The change in position of the methyl group from ortho-to-para increases the prediction of bioactivity of "Endothelin B receptor antagonist" activity. It has been widely reported that the vasospasm following subarachnoid hemorrhage ( $\mathrm{SAH}$ ) is prevented/reversed by Endothelin B receptor antagonists in animal model [17]. Endothelin receptor antagonists have been shown to decrease mortality and improve themodynamics in experimental models of heart failure. A number of studies suggest a role for ET-1 in pulmonary hypertension, as well as in systemic hypertension. A non-selective ET-1 receptor antagonist (bosen$\tan$ ) is currently used in the treatment of pulmonary hypertension. These studies provide rationale for the therapeutic use of $\mathrm{ET}(\mathrm{B} 1)$ receptor antagonists to relieve the vasospasm following $\mathrm{SAH}$, as well as other pathophysio-
Geometry of non-covalent interactions.

TABLE III

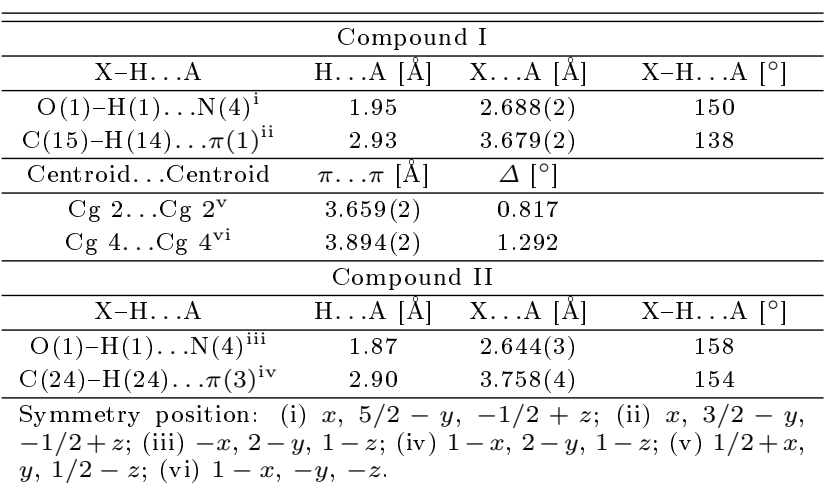

logical conditions involving possible ET-1-induced ET-1 release. In the graph, the green and blue lines are presented depicting the $P_{a}$ and $P_{i}$ values in compound II which shows the "Endothelin B receptor antagonist" activity at point 10 on the bioactivity scale. The slight variation in $P_{a}$ and $P_{i}$ values at scale point 7 shows the neutral activity of "Neuropeptide Y antagonist".

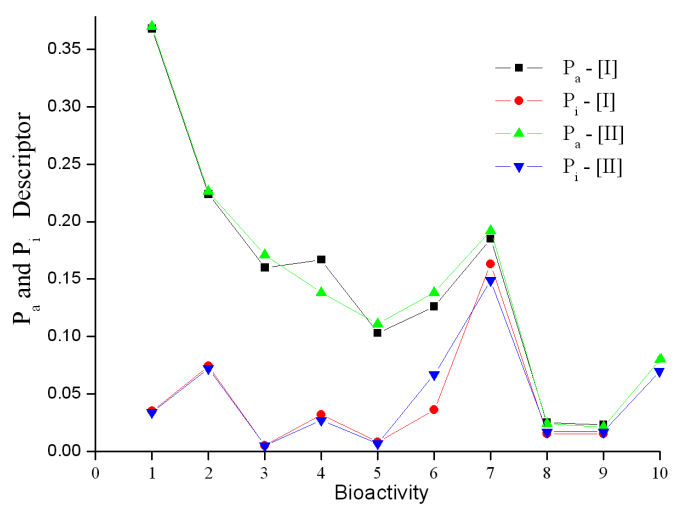

Fig. 5. Graphical representation of $P_{a}$ and $P_{i}$ descriptors depicting the bioactivity.

\section{Conclusion}

It can be concluded that the benzoic acid derivatives have wide range of bioactivities and their activities can be improved by the presence and the position of the methyl group. The detailed analysis of non-covalent interactions with their bioactivities has been intended in the present study and the change in position of methyl group from ortho-to-meta (into a more free electron withdrawing or donating position) depicts the increase in bioactivities. Bioactive predictions and X-ray crystallography suggest a structure-activity relationship for these benzoic acid derivatives and this orientation can be used as a template for further structure-based design. In structure-based drug design, the three-dimensional structure of a drug target interacting with these small molecules can be used to guide drug discovery. 


\section{Acknowledgments}

Author (J.D.) is grateful to University Grants Commission (UGC), New Delhi for research funding and Higher Education Department of Jammu and Kashmir Government for providing the research facilities.

\section{References}

[1] S. Srickland, T.R. Breitman, F. Frickel, A. Nerrenbach, E. Hadicke, M.B. Sporn, Cancer Res. 43, 5268 (1983).

[2] C.R. Unelius, G. Nordlander, H. Nordenhem, C. Hellqvist, S. Legrand, A.K. Borg-Karlson, J. Chem. Ecology 32, 2191 (2006).

[3] R. Arpana, N. Siddiqui, S.A. Khan, Ind. J. Pharm. Sci. 69, 10 (2007).

[4] Rajnikant, J. Dinesh, C. Bavnaish, Ind. J. Biochem. Biophys. 44, 458 (2007).

[5] D.A. Filimonov, V.V. Poroiko, Yu. Borodina, T. Gloriozova, J. Chem. Inf. Comput. Sci. 39, 666 (1999).

[6] V.V. Poroikov, D.A. Filimonov, Computer-Assisted Predictions of Biological Activity in Search for and Optimization of New Drugs, Vol. 1, Iridium Press, Moscow, 2001, p. 149.

[7] A.P. Suchkov, D.A. Filimonov, A.V. Stepanchikova, V.V. Poroikov, Environ. Res. 12, 327 (2001).
[8] S. Anzali, G. Barnickel, B. Cezann, M. Krug, J. Med. Chem. 44, 2432 (2001)

[9] G.M. Sheldrick, Program for the Solution of Crystal Structures, University of Gottingen, Federal Republic of Germany 1997.

[10] G.M. Sheldrick, Program for the Refinement of Crystal Structures, University of Gottingen, Federal Republic of Germany 1997.

[11] V.V. Poroikov, D.A. Filimonov, W.D. Ihlenfeldt, T.A. Gloriozova, A.A. LaguniN, Y.V. Borodina, A.V. Stepanchikova, M.C. Nicklaus, J. Chem. Inf. Comput. Sci. 43, 228 (2003).

[12] M. Zuccarello, R. Boccalett, A. Romano, R.M. Rapoport, Stroke 29, 1924 (1998).

[13] J. Tang, R. Xu, Y.M. Zhang, Acta Crystallogr. E 62 , o5820 (2006).

[14] T.B. Wei, R. Luo, H. Liu, Acta Crystallogr. E 62, o5883 (2006).

[15] Z. Li, J.Y. Yang, J.K. Wang, Heteroatom Chemistry 17, 664 (2006).

[16] S. Manohar, S.I. Khan, D.S. Rawat, Chem. Biol. Drug Des. 78, 124 (2011).

[17] F.H. Havaldar, A.R. Patil, e-chemistry 5, 374 (2008). 